INTERNATIONAL JOURNAL OF RESEARCHES IN BIOSCIENCES, AGRICULTURE AND TECHNOLOGY (c) VISHWASHANTI MULTIPURPOSE SOCIETY (Global Peace Multipurpose Society) R. No. MH-659/13(N) www.vmsindia.org

\title{
SYNTHESIS AND THERMAL STUDIES OF MULTIFUNCTIONAL MATERIAL DERIVED FROM 2, 6- DIHYDROXY ACETOPHENONE, PARAPHENYLENEDIAMINE AND FORMALDEHYDE
}

\author{
S. N. Niley ${ }^{1}$, K. P. Kariya ${ }^{2}$ and B. N. Berad ${ }^{3}$ \\ ${ }^{3}$ Department of Chemistry, Rastrasant Tukadoji Maharaj, Nagpur University, Nagpur-440033, India \\ ${ }^{2}$ Department of Chemistry, VMV Com. JMT Arts \& JJP Science College, Nagpur 440008, India \\ 1De partment of chemistry, Guru Nanak College, Ballarpur, India \\ sanjaynileyresearch@gmail.com
}

\section{Abstract:}

Te rpolymeric material was synthesize $d$ by the condensation of 2,6-dihydroxy ace tophenone, paraphenylenediamine, and formaldehyde in the pre sence of acid catalyst with 1:1:2 molar ratio of reacting monomers. The polymer has been characterized by UV-visible, IR and ${ }^{1} \mathrm{H}-\mathrm{NMR}$ s pe ctra. Thermal degradation curve has been discussed in order to determine its mode of decomposition, order of reaction, appare nt activation energy, frequency factor and free energy change. Freeman-Carroll and Sharp-Wentworth methods have been applied for the calculation of kine tic parameters while the data from the Freeman-Carroll method have been used to determine various thermodynamic parameters. This polymer is also found to possess optimum antibacterial activities.

Keywords: : Synthesis, Characterization, The rmal Studies

\section{Introduction}

The use of terpolymers in all spheres of life has been abundantly increased in recent years because of novelty and versatility. They occupy the pivotal position in the field of polymer science. The progress in this field has been extremely rapid as they are generally useful in packaging, adhesives, coatings, in electrical sensors,ion-exchangers, organome tallic semiconductors, activators, catalysts and thermally stable materials[1]. Due to global applications of polymeric materials, polymer science and technology have been developing rapidly and attracted much attention of polymer scientists. Polymers have been found to be very useful applications as adhesives, high temperature flame-resistant fibers, coating materials, semiconductors, catalysts, and ion exchange resins [2]. Varieties of researches regarding the thermal studies of polymers are emerging out to investigate their renewed applications for the betterment of mankind. Area of polymer reaction kinetics is enhanced by applying various model fitting kinetic equations in order to study its kinetic and thermodynamic aspects [3]. Much attention has been focused to synthesize the terpolymers by applying various synthetic techniques to examine its advanced applications. In the recent past, appreciable progress has been made in study of many ternary systems such as acrylonitrilemethylme thacrylate-methacrylic acid [4]. methylme thacrylate-styrene-bu tadiene [5] acrylonitrile-methyl acrylate-itaconic acid [6], styrene-acrylonitrile-methyl- acrylate [7]. Jadhav et.al studied synthesis, characte rization, and the rmal de gradation kine tics of co polymers derived from 2,2'-dihydroxybiphenylformalde hyde [8]. kinetics of thermal de gradation and estimation of lifetime for polypropylene particles and its effect on particle size, involving the use of single, and multiple heating rate techniques was studied by Paik et.al. [9].

\section{Materials And Methods}

All the chemicals used in the synthesis of new terpolymer resin were procured from the market and were of chemically pure grade. Whenever required they were further purified by standard methods like thin layer chromatography, reprecipitation, and crystallization, which are ge nerally used for the analytical purification purpose.

Pre paration of Sample

A mixture of 2,6-dihydroxyacetophenone (0.1 mol), Paraphenylenediamine $(0.1 \mathrm{~mol})$ and formaldehyde $(0.2 \mathrm{~mol})$ in molar ratio of $1: 1: 2$ in the presence of $2 \mathrm{M}(200 \mathrm{ml}) \mathrm{HCl}$ as a catalyst has been prepared in round bottom flask. The resultant mixture was refluxed over an oil bath for heating at $120^{\circ} \mathrm{C} \pm 2^{\circ} \mathrm{C}$ for $5 \mathrm{hrs}$ with occasional shaking to ensure thorough mixing. The resinous yellowish solid mass was obtained.

\section{Results And Discussion Characterization of synthesized resin}

The electronic spectrum of 2,6-DHAPDF-I is shown in (fig.2). The spectra depicted two characteristic bands. The band at $255 \mathrm{~nm}$ indicates the presence of $(>\mathrm{C}=\mathrm{O})$ group containing $\mathrm{C}-\mathrm{O}$ double bond in conjugation with an aromatic nucleus and can be accounted for $\pi$ $\Pi^{*}$ transition. The other less inte nse band at 355 $\mathrm{nm}$ may be due to $\mathrm{n} \quad \Pi^{*}$ electronic transition [10]. The IR spectra was shown in (Fig.3). The assignment of Vibrational fre quencies is based on 
the data available in the literature. A broad band appeared at $3286.90 \mathrm{~cm}^{-1}$ might be due to the stretching vibrations of phe nolic hydroxyl group exhibiting intermolecular hydrogen bonding which exist between $\mathrm{OH}$ grops of different polymerchain. The medium band at $3100 \mathrm{~cm}^{-1}$ is assigned to the $-\mathrm{NH}$ stretching vibration. The band obtained in the range of 1439.2, 1334.5 and $812.14 \mathrm{~cm}^{-1}$ is ascribed to bending, wagging and rocking vibrations of me thylene $\left(-\mathrm{CH}_{2-}\right)$ bridges. The band in the range of 1245 is due to $(\mathrm{C}-\mathrm{N})$ stretching. The medium broad band in the range of $694-892.18$ is attributed to substituted benzene ring. The band at $1705 \mathrm{~cm}-1$

may be due to the $>\mathrm{C}=\mathrm{O}$ stretching. The band at $1370.30 \mathrm{~cm}-1$ may be ascribed to phenolic C-O stretching. The NMR spectra of 2,6-DHAPDF-I terpolymer was shown in Fig.4 .The NMR spectrum of the 2,6-DHAPDF-I terpolymer exhibits signals in the region of $6.84 \delta(\mathrm{ppm})$, which may be due to the proton of aromatic ring (Ar- $\mathrm{H})$, and signals in the region $11.09 \delta(\mathrm{ppm})$ may be attributed to phenolic hydroxyl proton , methyle ne proton Ar-CH2-N moiety was inferred by the appearance of a weak singlet signal at 3.58-3.63 $\delta(\mathrm{ppm})$. The presence of a signal around $6.31 \delta(\mathrm{ppm})$ revels the presence of $-\mathrm{NH}$ bridges. Me thyl proton of $\mathrm{Ar}-\mathrm{Co}-\mathrm{CH}_{3}$ moiety may be identified by the intense peak in the region of $2.51 \delta$ (ppm).

The thermal degradation curve for the 2,6-DHAPDF-I terpolymer is shown in Fig. 5. Thermogram of 2,6-DHAPDF-I, depicted only one stage of decomposition without loss of water molecule. The first step of decomposition in the range of 200-600 $0 \mathrm{C}$ was due to loss of side chain $\left(-\mathrm{CH}_{2}-\mathrm{NH}-\mathrm{Ar}-\mathrm{NH}-, \mathrm{COCH}_{3}, 2 \mathrm{OH},-\mathrm{CH}_{2}\right)$ and partial degradation of aromatic nucleus (Calc $=95.02 \%$ and Found $=94.00 \%$ first stage of decomposition supported by exothermic peak in DTA [Fig.6]. Using half decomposition data and then applying the Sharp-Wentworth me thod[11], we obtained a Sharp-Wentworth plot for terpolymer as shown in Fig. 7. Ea calculated by this method was in agreement with the Ea calculated by Freeman-Carrol method [12], A thermal Ea plot and Freeman-Carrol plot for polymer is shown in Fig. 8 and 9 respectively. The the rmodynamic parameters for the polymer we re calculated on the basis of thermal Ea values, which are shown in Table-2.

From the data in Table-2. from the abnormally low values of the fre que ncy factor we concluded that the decomposition of 2,6DHAPDF-I polymer can be classified as a slow reaction for which there is no other obvious reason [13-16]. The negative value of $[\Delta \mathrm{S}]$ indicate that the activated polymer has more ordered structure than the reactants and that the reaction are slower, than normal. The decomposition of terpolyerm is known to obey first-order kinetics but not perfectly, as by Shrivastava and Juneja .

Acknowledgements: Author is thankful to Head of the Department of Chemistry, Rashtrasant Tukadoji Maharaj Nagpur Unive rsity, Nagpur for providing Laboratory facilities.

Table-1-Thermal degradation data of 2,6-DHAPDF-I Te rpolymer

\begin{tabular}{|c|c|c|c|c|c|}
\hline \multirow[b]{2}{*}{ Terpolymer } & \multirow{2}{*}{$\begin{array}{l}\text { Temperature } \\
\text { Range (oC) }\end{array}$} & \multirow{2}{*}{$\begin{array}{l}\text { Stage of } \\
\text { Decomposition } \\
\text { (DTA Peak) }\end{array}$} & \multirow[b]{2}{*}{ Species degraded } & \multicolumn{2}{|c|}{$\%$ mass loss } \\
\hline & & & & Found & Calc. \\
\hline $\begin{array}{l}2,6- \\
\text { DHAPDF-I }\end{array}$ & $200-600^{\circ} \mathrm{C}$ & First $($ Exo, b) & $\begin{array}{l}\text { Loss of side chain }\left(-\mathrm{CH}_{2}-\mathrm{NH}-\mathrm{Ar}-\right. \\
\left.\mathrm{NH}-, \mathrm{COCH}_{3}, 2 \mathrm{OH},-\mathrm{CH}_{2}\right) \text { and } \\
\text { partial degradation of aromatic } \\
\text { nucleus }\end{array}$ & 94.00 & 95.02 \\
\hline
\end{tabular}

Table 2: Kinetic parame te rs for 2,6-DHAPDF-I Te rpolymer resin

\begin{tabular}{|c|c|c|c|c|c|c|c|c|c|}
\hline \multirow[t]{2}{*}{ Terpoly mer } & \multirow{2}{*}{$\begin{array}{l}\text { Decompo Temp } \\
\text { T } \\
\left({ }^{\circ} \mathrm{C}\right)\end{array}$} & \multirow{2}{*}{$\begin{array}{l}\text { Half } \\
\text { Decomp } \\
\text { Temp } \\
\text { (OC) }\end{array}$} & \multicolumn{2}{|c|}{$\begin{array}{l}\text { Activation Energy } \\
\mathrm{kJ} / \text { mole }\end{array}$} & \multicolumn{5}{|c|}{ Kinetic Parameters by FC } \\
\hline & & & FC & sw & $\begin{array}{l}\mathbf{S S} \\
(\mathrm{J})\end{array}$ & $\begin{array}{c}\Delta \mathbf{A F} \\
(\mathbf{k J})\end{array}$ & \begin{tabular}{|l|}
$Z$ \\
$\left(S^{-1}\right)$
\end{tabular} & $\begin{array}{l}\text { S* } \\
\text { (J) }\end{array}$ & $\mathbf{n}$ \\
\hline 2,6-DHAPDF-I & $200^{\circ} \mathrm{C}$ & 400 & 28.24 & 31.00 & -130.31 & 67.43 & 25.11 & -20.76 & 0.96 \\
\hline
\end{tabular}




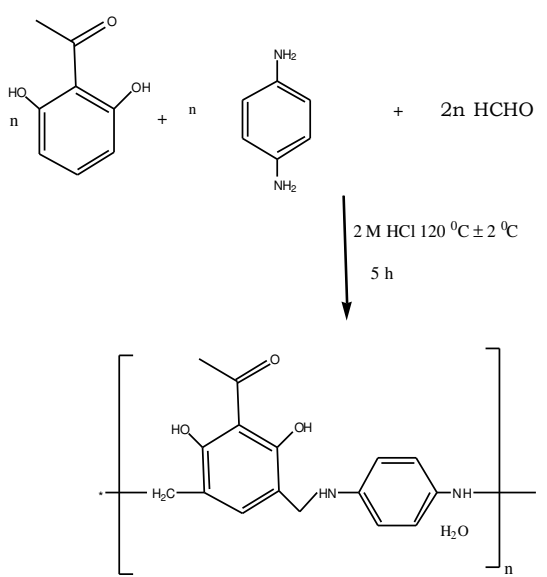

Figure 1: Reaction for 2,6-DHAPDF-I Te rpolymer Resin

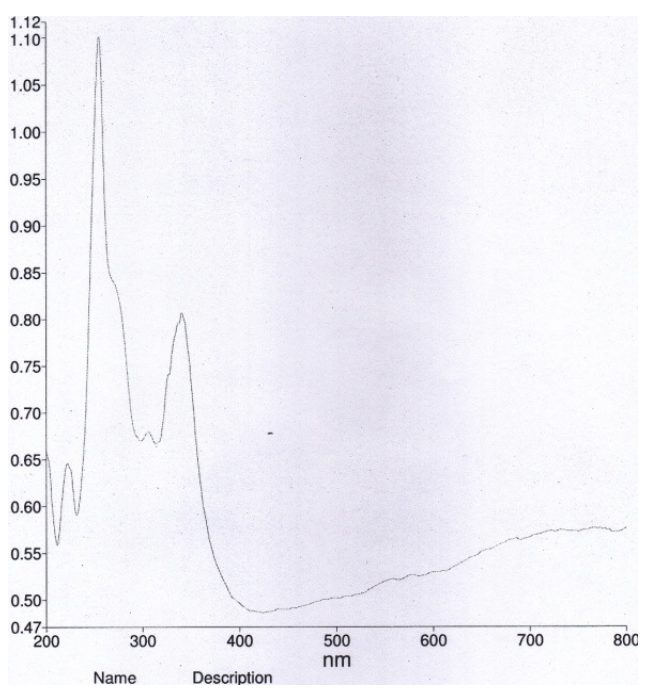

Figure 2: UV Visible Spectrum of 2,6DHAPDF Te rpolymer resin

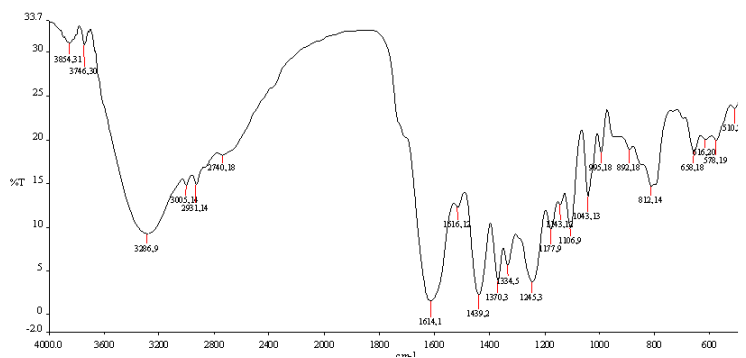

Figure 3: IR-Spectral Data of 2,6-DHAPDF-I Te rpolymer resin

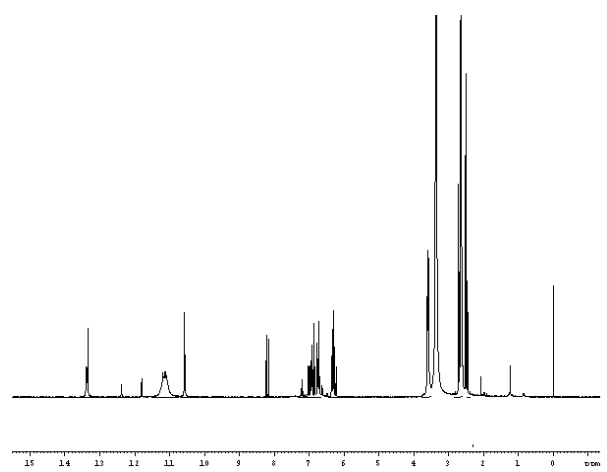

Figure 4: ${ }^{1} \mathrm{H}$ NMR Spectra of 2,6-DHAPDFITe rpolymer Resin

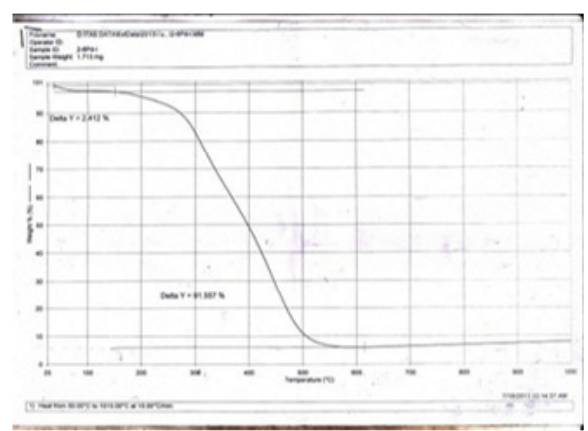

Figure 5: TGA Graph for 2,6-DHAPDF-I

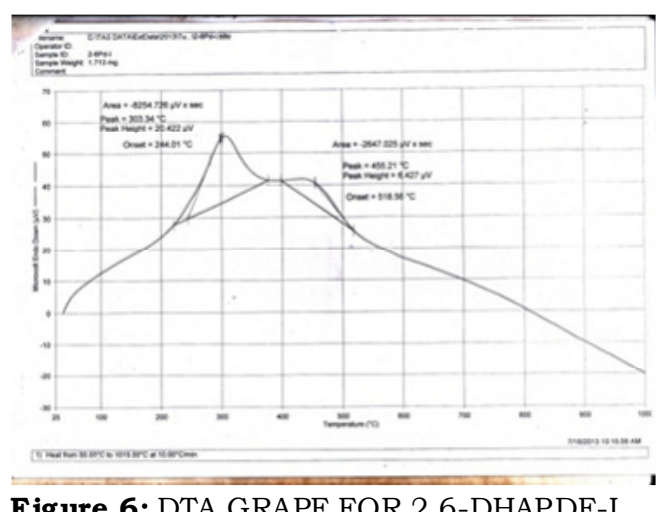

Figure 6: DTA GRAPF FOR 2,6-DHAPDF-I

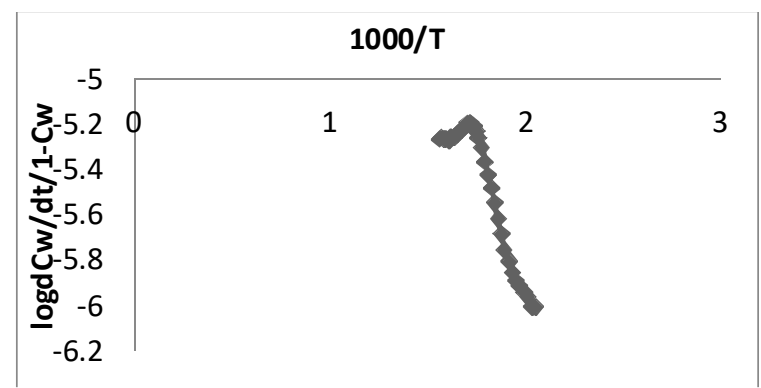

Figure 7: Sharp-Wentworth plot of 2,6DHAPDF-I Terpolymer Resin 


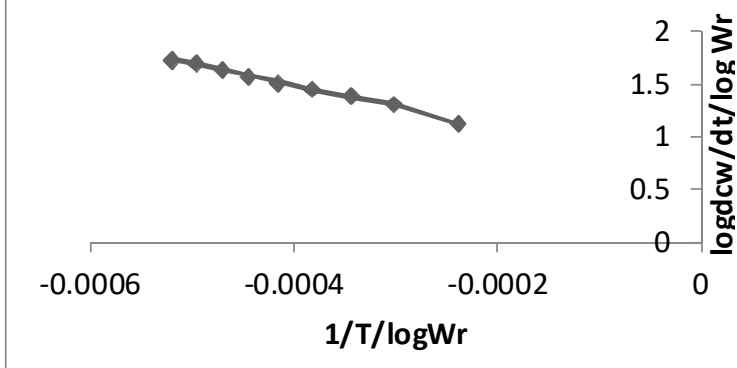

Figure 8: Thermal Activation Energy Plot of 2,6DHAPDF-I Terpolymer Resin

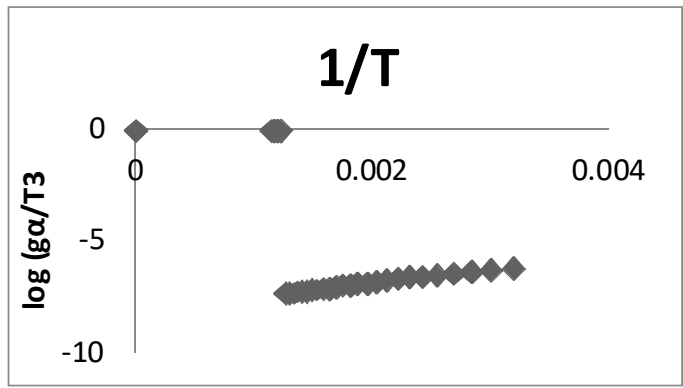

Figure 9: Freeman-Carroll plot of 2,6-DHAPDFI Terpolymer Resin

\section{References}

1. Masram, D.T.; Kariya, K. P. and Bhave, N.S.; (2010). Ele ctrical conductivity study of resin synthesized from salicylic acid, butylenediamine and formaldehydeArch. Apll. Sci. Res.2(2): 153-161

2. Shah, B. A.; Shah, A. V.; Bhandaria, B. N. and Bhatt, R. R.;(2008): Synthesis, Charecterization and Chelation IonExchange Studies of a Resin CopolymerDerived from 8-HydroxyquinolineFormalde hyde-Catechol. J. Iran. Chem. Soc. 5(2): 252-261.

3. Fernandez B.; Arlas, D.; Rueda, L.; Stefani, P.M.; K.Mondragon, and A. Eceiza, (2007). Kinetic and thermodynamic studies of the formation of a polyurethane based on 1,6 hexamethylene diisocyanate and poly( carbonate-co-ester)diol, The rmochimica Acta, 459(2), 94-103.

4. Simionescu C.I, and A. Liga, (1977). Researches in the terpolymerization fieid.VIII. Theore tical structural study of the high conversion acrylonitrile-methacrylic acid- methyl methacrylate terpolymer, Revue Roumaine de Chimie, 22(1) 49-54.
5. Furukawa, J.; Iseda, Y.; Haga, $\mathrm{K}$ and Kataoka, N (1970). New information on the altering copolmerization of butadiene-1,3 with acrylonitrile, Journal polymer science part A-1, 8(5) 1147-1163,

6. Naguib, H. F.; Mokhtar, S.M.; Ali, R.O, and M. Z. Elsabee, (2003) Te rpolymerization of e thyl methacrylate, $\mathrm{N}$-phenylmaleimide, and itaconic acid. Journal Polymer Science A 41 (20) 3180-31 87,

7. Hirooka, M.; Yabuuchi, H.; Kawasumi, S. and Nakaguchi, K. (1973) Complex copolymerization of vinyl compounds with alkyaluminum halides. Journal Polymer Science A-1, 11(6) 1281-1306

8. Jadhav, M M.; Paliwal, L.J.; and Bhave, N.S.(2006)Resin II : the rmal degradation studies of terpolymer resins derived from 2,2'-dihyd roxybiphenyl, urea, and formaldehyde," Journal of Applied Polymer Science, 101 (1) 227-232.

9. Paik P.and Kar, K.K.; (2008).Kinetics of thermal degradation and estimation of life time for polypropylene particles: effects of particle size. Polymer Degradation and Stability. 93(1) 24-35.

10. Voge1 A. I., "Textbook of practical organic chemistry," Longman Scientific and Technical, U.K. (1989).

11. Freeman ES, Caroll B .(1958) The application of the rmoanalytical techniques to reaction kine tics. The thermogravime tric evaluation of the kine tics of the decomposition of calcium oxalate monohydrate. J Phys Chem ;62: 394-397.

12. Sharp JB, Wentworth SA .(1969) Kinetic analys is of thermogravime tric data Anal Che; 41: 2060-2062.

13. Masram DT, Bhave NS, Kariya KP (2010). Kinetics study of thermal degradation of resin derived from salicylaldehyde, ethylenediamine and formaldehyde. E J Chem ; 7:564-568.

14. Nielsen CA, Pie rini P, Fuh S (1993). Thermal and thermo oxidativedegradation of poly $(\mathrm{p}$ phenylene-cis-benzobisoxazole) (PBO):determination of kinetics and reaction products. J Fire Sci. ;1 1:156-71

15. Furniss BS, Hannaford AJ, Smith PWG, Tatchell AR . Vogel's text book of practical organic chemistry. England: AddisonWesley Longman Ltd; 1998.

16. Ozawa $T$ (1985) Critical investigation of methods for the rmoanalytical data. J. Thermal Analys is and Calorime try ;3(2):601617. 